\title{
A CASE OF MASSIVE LIPOMA OF THE MEDIASTINUM
}

\author{
RAYMOND S. LEOPOLD, M.D. \\ PHILADELPHIA
}

The presence of a lipoma in the anterior mediastinum, weighing 17 pounds 6 ounces, is so unusual that I wish to record my notes of a case in full.

\section{REPORT OF CASE}

R. K. B., aged $37 \frac{1}{3}$ years, American; clergyman; married. Family history negative. Aside from diseases of childhood, patient was a healthy child and an athletic boy. At 16 he was kicked in the abdomen by a horse, and his recollection of this was a feeling of distress, at times, for about one year. Never had an injury of the chest; never had pleurisy, pneumonia or pericarditis. He had a deep cough, similar to the one developed with the last illness, about five years before, lasting about a month.

- Present Illness.-Patient was well until about seventeen months ago when he sought medical advice for a deep, hollow cough which appeared while in apparent physical fitness. Gradually, this cough became more persistent and was referred to the throat, just above the sternum, described as of an irritating character. Color was good, no constitutional symptoms, no laryngeal symptoms, but an occasional deep sigh and a sensation of a slight.substernal oppression. In about four months this amounted to shortness of breath and an occasional wheezing. He slept quietly and well, preferably on the left side, with little or no cough at night.

During the next five months the cough and dyspnea grew rapidly worse and with it a beginning feeling of heaviness in the chest, and exertion was accompanied by an alarming dys,pnea. It became necessary to sit upright, or leaning forward. Almost constantly leaning forward; he could not lie on his back. Weight loss, 10 pounds.

At nine months, roentgen-ray treatment being instituted, his condition seemed to improve for a few weeks, but while his cough became less harassing, the dyspnea and oppression again returned and increased. He grew weaker and thinner in the face and arms, slight edema of the lower limbs appeared, and he could sleep only in the knee chest position, while the slightest exertion produced painful attacks of respiratory embarrassment.

By the fifteenth month he had to lean forward resting his chest on a table constantly, the air-hunger was continuous. The edema of the lower extremities, genitalia and abdomen was extreme. Marked cyanosis of the upper extremities and especially the head appeared; later, numbness of the arms, mental torpor, and finally, a distressing struggle for air preceded a mechanical death.

REPORT OF ROENTGENOGRAPHIC EXAMINATION OF THE THORACIC CAVITY

This examination was made at nine months by Dr. Walter $C$. Barker. His report was as follows:

The anteroposterior view shows a shadow of greater density than normal, extending from the third rib to the diaphragm. This shadow fills the whole breadth of the chest, except a small area of the lower right side. The lateral view shows a dense shadow with a smooth and sharp outline, bulging the anterior wall of the thoracic cavity and extending downward and backward from the third rib to the diaphragm. At the broadest part it almost reaches 
posteriorly to the spinal column. The heart shadow is pushed downward and backwarl, and the lung shadow is mostly above, with a small air space showing below.

Diagnosis: Large primary tumor in the anterior mediastinum.

The record of early physical signs are unobtainable. A persistent hollow cough, increasing in severity and accompanied by an occasional shortness of breath, and later a pronounced dyspnea, constitute the earliest referable symptoms. Yet at nine months, physical examination

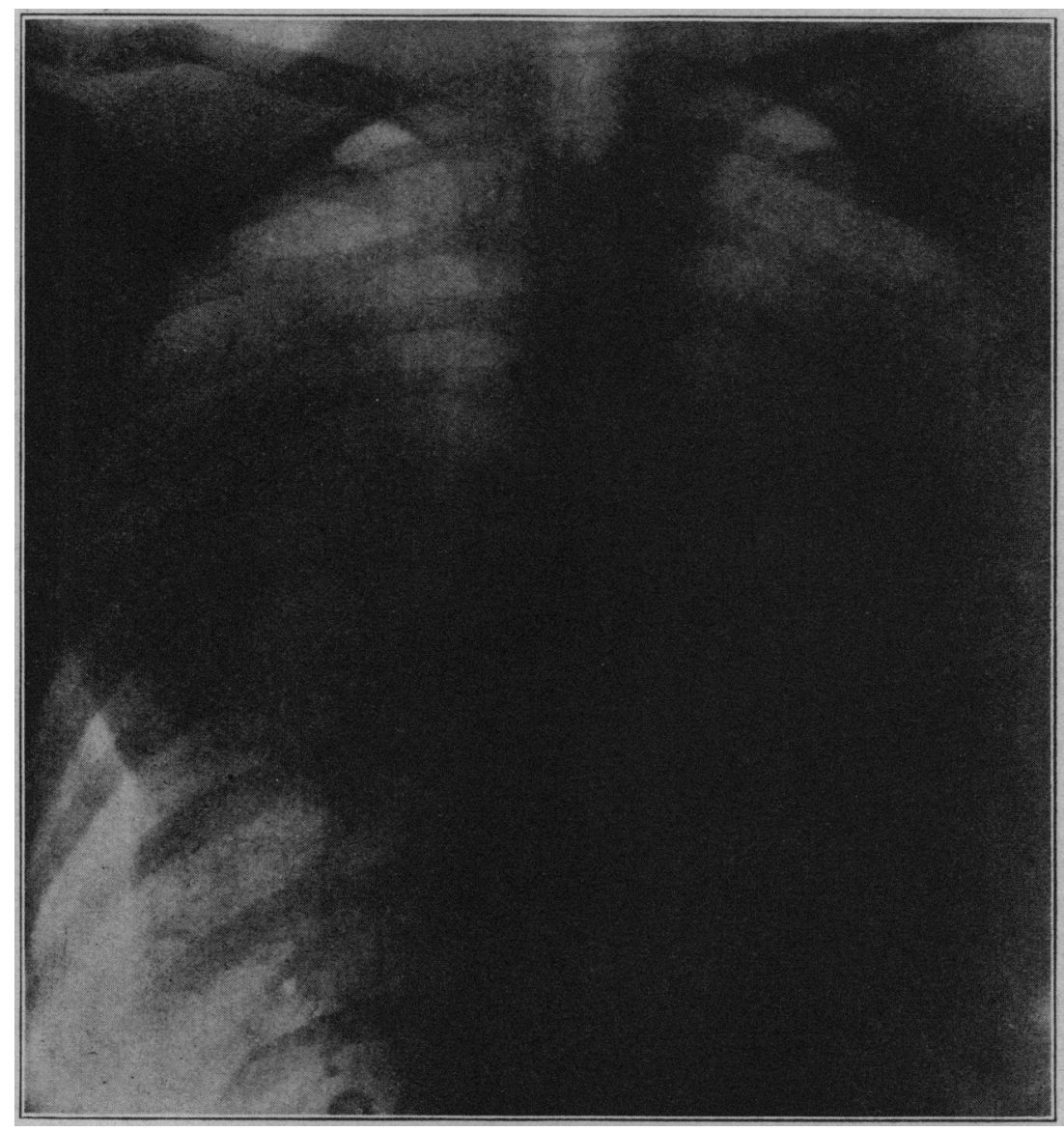

Fig. 1.--Anteroposterior view of chest showing a large tumor. The dark shadow in the lower part of the thorax is cast by the heart; the light shadow at the right and above at the apices is cast by the lungs.

and roentgen-ray examination demonstrated a tumor filling about fourfifths of the chest. There was no pain, no positive emaciation or cachexia, no metastasis, no dysphagia, no aphonia.

Necropsy:-A necropsy was made five and one-half hours after death. Rigor mortis absent. Well developed body, but head and arms thin and of a dusky 
bluish hue. Remainder of body extremely edematous. Lower extremities water logged and of twice their normal size. Thoracic cavity: pressure increased, entire cavity apparently filled with an indefinite, lobulated mass conforming to the thoracic arch and extending from the apex to the diaphragm. This mass seems to be attached only at one point, just below the sternal notch, and by only a frail strand of loose adhesivelike bands, easily dissected free with the fingers. The base and posterior surface being found free, the entire

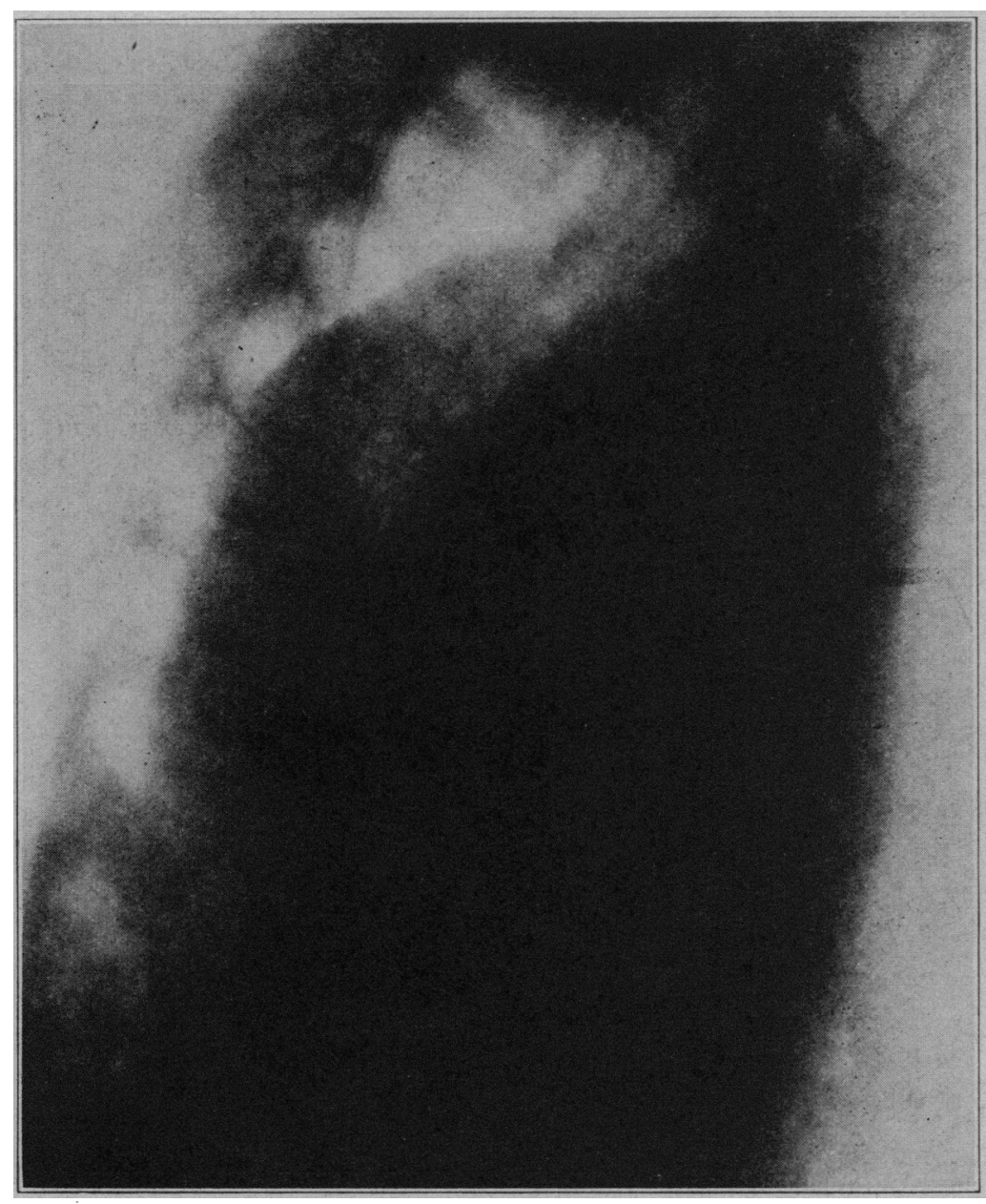

Fig. 2.-Lateral view of chest; shows the shadow of the tumor filling a large part of the thorax. The lungs are crowded above and behind the tumor, and the heart is pushed back and below; the growth being in the anterior mediastinum.

mass is easily delivered, disclosing the heart vessels and lungs compressed along the vertebral column and low in the posterior mediastinum. The heart is very small and pale, measuring approximately 7 by 8 by $6 \mathrm{~cm}$. Lungs measure approximately, 5 by 15 by $3 \mathrm{~cm}$., very dark, and of a liverlike con- 
sistence with little crepitation. The peritoneal cavity is filled with a pale transudate, while all the abdominal viscera exhibit extreme degrees of passive congestion.

Pathologic Findings.-A sharply defined, soft fluctuating tumor, covered by a dense tough fibrous capsule which seems to divide it into multiple rounded lobules. On cross section it is apparently a mass of pale yellowish, greasy, fatty tissue. Weight, 17 pounds 6 ounces, measuring 31 by 30 by $15 \mathrm{~cm}$. The anterior surface is convex conforming in general outline and appearance to the thoracic concavity, narrowed at the apex and broad and squatty at the base, with a broad notch midway of the base. The posterior surface is irregular in outline with a vertical concavity about midway, approximately $15 \mathrm{~cm}$. wide at its widest point and about $8 \mathrm{~cm}$. deep. This concavity, which housed the heart, vessels and lungs, is more or less completely lost at the apex while fusing with the notch at the base. All fresh sections stained with sudan III a uniform deep red with few fine grayish stripings of connective bands. The entire tumor developed and fixed well in Kaiserling.

Microscopically, the tumor is composed entirely of masses of fat cells lying in a vascular connective tissue matrix. The individual cells in general are

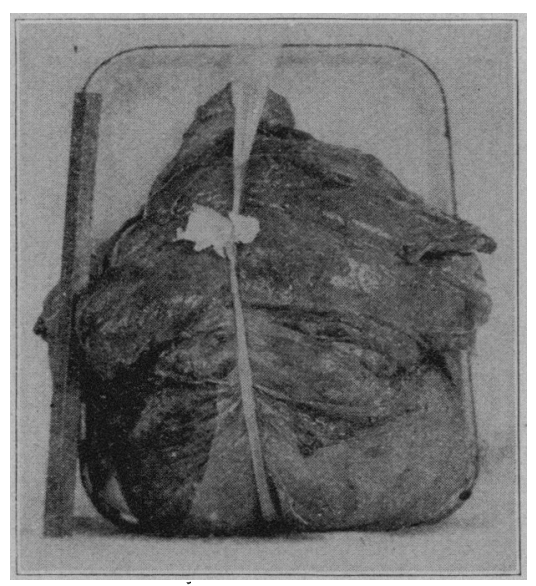

Fig. 3.-The tumor after removal at necropsy, supported against a waiter with a 12 -inch ruler standing beside it.

larger than usual fat cells and are round or oval, although in sections taken from about the base they are compressed and flattened. All sections stain perfectly with osmic acid-sudan III.

Medical literature reveals a surprising scarcity of contributions of primary tumors of the mediastinum. ${ }^{1}$ While occasional records of teratoma, ${ }^{2}$ dermoid, ${ }^{3}$ cysts, ${ }^{4}$ fibroma and others tumors ${ }^{5}$ appear. I have been able to find only four cases of lipoma reported.

1. Behrens: Weekly Bull. St. Louis M. Soc. 139: 1911.

2. Atlas: Allg. Wien. med. Ztg., 1894. Becker: Internat. Clin. 19: 1919.

3. Godlee: Proc. Roy. Med. Soc., London, 1908. Kaestle: München. med. Wchnschr. 1: 1909.

4. French: P'roc. Roy. Med. Soc., Lond., 1907. Blackader: Arch. Pediat. 28: 1911. Rose: Lancet 2:1308, 1893.

5. Hare: Mediastinal Disease, Philadelphia, Lea \& Febiger, 1889. Edwards: Arch. Pediat. 6:1889. Roberts: Lancet 2: 1912. Nichols: Boston M. \& S J. 1897. 
Beatson ${ }^{6}$ records having removed a lipoma of about the size of an orange from the superior mediastinum of a man, aged 45 . This presented just above the manubrium sterni and had been increasing slowly for five years, but was not causing any inconvenience. Hare ${ }^{5}$ collected three cases, of none of which was he able to obtain a thorough description. All patients were males, the ages of twa were given as 38 and 50 . In one case the tumor was specified as located in the anterior mediastinum. All patients had marked dyspnea. One patient had marked cyanosis of the face. In two cases the pericardium was involved. The duration of one case is given as a little more than one month. All patients died.

6. Beatson: Glasgow M. J. 1:57, 1899. 